\title{
Multivariate Threshold Models: TVARs and TVECMs*
}

\author{
Ana Beatriz C. Galvão**
}

\begin{abstract}
In this paper, I review recent developments on modelling macroeconomic variables with non-linear VARs. Specifically, the class of threshold VARs, including systems with threshold cointegration, is discussed. Techniques for specification, estimation, testing, computing impulse responses and forecasting are presented, including hints for practitioners. In addition, I analyze recent results on the evaluation of this class of models, providing guidance on the application of these models. Finally, a TVAR is applied to extract the information of the spread to predict recessions; and a TVECM is employed to test threshold cointegration in the context of the term structure of interest rates.
\end{abstract}

\section{Resumo}

Nesse artigo, eu faço uma resenha sobre as contribuições recentes em modelagem de variáveis macroeconômicas usando modelos VAR não-lineares. Especificamente, os modelos chamados "Threshold VAR" são discutidos, além de modelos que permitam "threshold cointegration". Técnicas para estimar, especificar, testar, calcular funçōes de impulso-resposta, e prever são apresentadas, incluindo algumas dicas para pesquisadores. Além disso, eu analiso os resultados da avaliação desses modelos realizados recentemente, de forma a orientar a aplicação desses modelos. Finalmente, um TVAR é aplicado para extrair informação do spread para prever recessōes; e um TVECM é empregado para testar "threshold cointegration" no contexto da estrutura a termo da taxa de juros.

Key Words: threshold vector autoregressive models, threshold co integration .

JEL Code: C32, E37 .

* This paper has been prepared for the short-course on the topic presented by the author at the Meeting of the Brazilian Society of Econometrics at Nova Friburgo, Brazil, 2002. Some parts have been drawn up from my previous papers with a co-author Mike Clements.

\footnotetext{
**Ibmec - SP, Rua Maestro Cardim, 1170, São Paulo - SP, Phone: ++55-11-3175-2300, anabg@ibmec.br
}

Brazilian Review of Econometrics Rio de Janeiro v.23, $\mathrm{n}^{\mathrm{O}} 1$, pp.143-171 May 2003 


\section{Introduction.}

Thresholds are everywhere. Small changes in the exchange rate do not affect prices, but large changes certainly do. Long and shortterm interest rates may not be converging to their equilibrium position most of the time, but when the deviations are large enough, convergence prevails. The spread between the long- and the shortterm interest rates helps to predict output growth in the US, but only when the spread is negative. The transmission of international shocks may depend on the quality of economic fundamentals of the country that suffers shocks.

This paper reviews the modelling procedures employed for specifying, estimating and testing multivariate models with thresholds. Thresholds together with an observed transition variable define regimes with different dynamic behavior for the endogenous variables of the system. These estimated threshold VARs or VECMs are employed for forecasting and to analyze asymmetric responses to shocks. We exemplify these techniques modelling the spread as leading indicator to predict the probability of US recessions and analyzing threshold cointegration between long- and short-term interest rates. Results on the evaluation of threshold models are discussed, proving guidance on the application of these models.

\section{Modelling TVARs.}

Threshold vector autoregressive models have regimes defined by an observed variable $w_{t-d}$ and by a transition function $F\left(w_{t-d}\right)$. Let us assume that $y_{t}$ is a $K \times 1$ vector of endogenous variables $y_{t}=\left(y_{1 t}, \ldots, y_{K t}\right)^{\prime} ; c$ is a $K \times 1$ vector of constants; $A_{i, j}$ is a $K \times K$ matrix of coefficients of regime $i$ and of lag $j$, where $s$ is the number of regimes with different autoregressive parameters with $i=1, \ldots, s$, and $p$ is the autoregressive order with $j=1, . ., p$, a threshold VAR 


\section{Ana Beatriz C. Galvão}

is written as:

$$
y_{t}=c_{i}+\sum_{j=1}^{p} A_{i, j} y_{t-j}+\varepsilon_{t, i} \text { if } r_{i-1}<w_{t-d} \leq r_{i}
$$

where $\varepsilon_{t, i}$ is a $K \times 1$ vector of innovation process with zero mean, variance equal to $\Sigma$ and $E\left(\varepsilon_{t} \varepsilon_{l}^{\prime}\right)=0$ for $l \neq t$. The transition variable $w$ is one of the variables in the $y_{t}$ vector. This non-linear multivariate model supposes that $p$ is the same for each variable and regime, and that the transition function is the same for each equation.

A threshold VAR with two regimes is written as:

$$
\begin{aligned}
y_{t}= & \left(c_{1}+A_{1,1} y_{t-1}+\ldots+A_{1, p} y_{t-p}\right)\left(I\left(w_{t-d} \leq r\right)\right)+ \\
& \left(c_{2}+A_{2,1} y_{t-1}+\ldots+A_{2, p} y_{t-p}\right)\left(1-I\left(w_{t-d} \leq r\right)\right)+\varepsilon_{t}
\end{aligned}
$$

where $I($.$) is an indicator function. An example of a 2R-TVAR in$ the literature is to model the output growth and the spread between long- and short-term interest rates with US data (Galvão, 2002). The spread only helps to predict output growth when its value is negative. This implies a model with the spread as transition variable, the threshold value near zero and that the values of $a_{21}$ in the $A_{2}, j$ matrices are statistically equal to zero.

A threshold VAR with three-regimes is written as:

$$
\begin{gathered}
y_{t}=\left(c_{1}+A_{1,1} y_{t-1}+\ldots+A_{1, p} y_{t-p}\right)\left(I_{1}\left(w_{t-d} \leq r_{1}\right)\right)+ \\
\left(c_{2}+A_{2,1} y_{t-1}+\ldots+A_{2, p} y_{t-p}\right)\left(1-I_{1}\left(w_{t-d} \leq r_{1}\right)\right) I_{2}\left(w_{t-d} \leq r_{2}\right)+ \\
\left(c_{3}+A_{3,1} y_{t-1}+\ldots+A_{3, p} y_{t-p}\right)\left(1-I_{2}\left(w_{t-d} \leq r_{2}\right)+\varepsilon_{t} .\right.
\end{gathered}
$$


One of the implications of the expectation theory of the term structure is that the spread between the long- and the short-term interest rate must predict future changes in the short-term rate during the period of the maturity of the long-term rate. When the relationship between short-term rate and the spread is modelled with a 3R-TVAR, Clements and Galvão (2003b) show that the expectations theory only holds in the third regime when the spread is large and positive, but the effect of the spread on the short-rate is dissimilar to the other two regimes.

\subsection{Estimation.}

Assume that $Y_{k}=\left(y_{k 1}, \ldots, y_{k T}\right)$ is a vector of the $k^{\text {th }}$ endogenous variable of sample size $T, \varepsilon_{k}=\left(\varepsilon_{k 1}, \ldots, \varepsilon_{k T}\right)$ is the vector of residuals of the equation of the $k^{\text {th }}$ endogenous variable, $X_{i, t-1}=\left(1, y_{t-1}, \ldots, y_{t-p}\right)$ is the matrix of explanatory variables at time $t$ and for each regime with different autoregressive parameters, so for all the regimes $i=1, . ., s, X_{t-1}=\left(X_{1, t-1}, \ldots, X_{s, t-1}\right)$ is a $(1 \times(\operatorname{skp}+s))$ matrix, consequently for the whole sample the matrix of explanatory variable is $X=\left(X_{0}, \ldots, X_{T-1}\right)$. The vector of parameters of $k^{t h}$ equation is $\theta_{k}=\left(\beta_{k, L}, \beta_{k, N L}\right)^{\prime}$, where $\beta_{k, L}$ is $((s K p+s) \times 1)$ vector of constants and autoregressive parameters and $\beta_{k, N L}$ is a vector of the parameters of the non-linear function. In a two-regime TVAR, for example, $\beta_{k, N L}=\left[d, r_{k}\right]$. Note that because of the VAR representation, the vector of parameters in the transition function is the same for each equation, that is, $\beta_{l, N L}=\beta_{m, N L}$ for all $l, m=1, \ldots, K$. Therefore, a non-linear VAR is written as:

$$
\left[\begin{array}{c}
Y_{1} \\
Y_{2} \\
\vdots \\
Y_{K}
\end{array}\right]=\left[\begin{array}{c}
m_{1}\left(X, \theta_{1}\right) \\
m_{2}\left(X, \theta_{2}\right) \\
\vdots \\
m_{K}\left(X, \theta_{K}\right)
\end{array}\right]+\left[\begin{array}{c}
\varepsilon_{1} \\
\varepsilon_{2} \\
\vdots \\
\varepsilon_{K}
\end{array}\right]
$$




\section{Ana Beatriz C. Galvão}

where $m_{i}($.$) is a non-linear function of X$ and $\theta_{i}$ such that $m_{i}($.$) is a$ vector $(T \times 1)$. This system is vectorized to be written in a compact form as

$$
\mathbf{y}=\mathbf{m}(\mathbf{x}, \theta)+\mathbf{u}
$$

where $\mathbf{y}, \mathbf{m}(\mathbf{x}, \theta)$ and $\mathbf{u}$ are $(T K \times 1)$ vectors, $\mathbf{x}$ is a $(T K \times(s K p+s))$ matrix and $\theta=\left(\theta_{\mathbf{1}}, . ., \theta_{\mathbf{k}}\right)^{\prime}$.

Thus, given the covariance matrix of the residuals $\Sigma$, the sum of squared residuals function is

$$
S(\theta)=(\mathbf{y}-\mathbf{m}(\mathbf{x}, \theta))^{\prime}\left(\hat{\boldsymbol{\Sigma}}^{-\mathbf{1}} \otimes \mathbf{I}_{\mathbf{T}}\right)(\mathbf{y}-\mathbf{m}(\mathbf{x}, \theta))
$$

and the least squares estimator is

$$
\hat{\theta}=\underset{\theta \in \Theta}{\operatorname{argmind}} \operatorname{det}(\hat{\boldsymbol{\Sigma}}(\theta))
$$

where $\hat{\Sigma}(\theta)$ is calculated as $1 / T \sum_{i=1}^{T} \varepsilon_{t} \varepsilon_{t}^{\prime}$. This is equivalent to the maximum likelihood estimator under the assumption that the residuals are normally distributed (Gallant, 1987).

Conditional on the parameters of the transition functions $\theta_{\mathrm{NL}}=$ $\left(\beta_{1, N L}, \ldots, \beta_{\mathbf{K}, \mathbf{N L}}\right)$, the estimation problem is linear. Thus, the sum of squared residuals function can be concentrated with respect to $\theta_{\mathrm{NL}}$ :

$$
S\left(\theta_{L} \mid \theta_{N L}\right)=\left(\mathbf{y}-\theta_{\mathbf{L}}^{\prime}\left(\theta_{\mathbf{N L}}\right) \mathbf{x}\right)^{\prime}\left(\hat{\mathbf{\Sigma}}^{-\mathbf{1}} \otimes \mathbf{I}_{\mathbf{T}}\right)\left(\mathbf{y}-\theta_{\mathbf{L}}^{\prime}\left(\theta_{\mathbf{N L}}\right) \mathbf{x}\right)
$$

Threshold VARs are estimated evaluating $\operatorname{det}(\hat{\Sigma}(\theta))$ for each possible value of threshold in the case of two-regime models, and for each 
possible combination of thresholds, when three-regime models are estimated; that is, for all $\theta_{\mathbf{N L}} \in \Theta$. Then, $\hat{\theta}$ is a vector of parameters that minimizes $\operatorname{det}\left(\hat{\Sigma}\left(\theta_{\mathbf{L}} \mid \theta_{\mathbf{N L}}\right)\right)$ for $\theta_{\mathbf{N L}} \epsilon \Theta$. Tsay(1998) suggests to minimize the $\operatorname{tr}\left(\hat{\Sigma}\left(\theta_{\mathbf{L}} \mid \theta_{\mathbf{N L}}\right)\right)$, showing that the estimator is consistent and that the estimates of $\theta_{\mathbf{L}}$ are asymptotically normal.

An important point is the definition of upper and lower limits of the allowed parameters in $\Theta$, that is, $[\underline{\theta}, \bar{\theta}]$. These limits are normally defined by the minimum proportion of observations that one wants to have in each regime. Note that when only a small number of observations is allowed in each regime, the least square estimates of the autoregressive parameters cannot be precise. In addition, the estimation may define a regime for the outliers. Exercises presented by the literature normally define that each regime needs to have at least $10 \%$ of the observations (see, e.g., Hansen (2000b) and Hansen and Seo (2002)).

\subsection{Testing Linearity.}

The test of linearity with a $\operatorname{VAR}(p)$ under the null and a $\operatorname{TVAR}(\mathrm{p})$ under the alternative implies nuisance parameters that are not identified under the null $\theta_{\mathbf{N L}}$. In such case, the distribution of the test is non-standard and non-similar, implying that tabulation is not possible. Hansen (1996) solves this problem by proposing a transformation to compute the asymptotic distribution employing simulation, given that the distribution is data-dependent. The nonstandard distribution is obtained for a statistic that is equal to the supremum of a set of Wald statistics calculated for each allowable threshold value $\left[r_{L}, r_{U}\right]$.

Specifically, the test consists in computing $\sup _{r \in\left[r_{L}, r_{U}\right]} W(r)$, which has a distribution that depends on the moments of the matrix of explanatory lag variables and on a random function with $\operatorname{argument} r$. If the thresholds were known, the distribution of the 
statistic would be chi-squared. As long as the thresholds are unknown, the asymptotic distribution and the exact p-value can be calculated using a simulation process to build the random function. Hansen (2000b) also describes an algorithm that can be employed to calculate the bootstrap approximation of this distribution. The algorithm consist in simulating data using bootstraps from the residuals of the model under the null hypothesis (the linear one) and then using this data to estimate a threshold model and to compute the supWald statistic. Both procedures can be corrected to take into account heteroscedasticity in the residuals of the null hypothesis.

Clements and Galvão (2003a) and Hansen and Seo (2002) apply similar methods to test threshold non-linearity in a VECM using bootstrap to obtain the empirical distribution. The earlier authors define a supLR statistics and the latter a supLM. This is so because data can be easily simulated by bootstrap from a VAR or a VECM needing only definition of initial values.

An alternative is the linearity test proposed by Tsay (1998) which is the vector extension of the Tsay (1989) test for non-linearity based on an 'arranged regression'. The problem in testing a threshold becomes a problem in testing a change-point. Unlike likelihoodbased approaches, which rely on simulated critical values, the test has an asymptotic chi-squared distribution. The arranged regression orders the observations according to the size of $w_{t-d}$, and assumes that the threshold variable $\left(w_{t}\right)$ and the delay, $d$, as well as the autoregressive order, $p$, are known. The model is then estimated by recursive LS, and the predictive residuals are obtained. Under the null that the model is linear, these residuals are uncorrelated with the explanatory variables in the arranged regression. The test is constructed by regressing the (standardized) predictive residuals on the explanatory variables, and testing for the significance of the latter. The simulation results presented by Tsay (1998) indicate that this 
test has a good power when $d$ is correctly specified.

\subsection{Confidence interval for the threshold.}

Hansen (2000a) and Gonzalo and Wolf (2001) present techniques to obtain confidence interval for the threshold. Hansen (2000a) shows that the problem of having one threshold dividing the sample into two sub-groups is equivalent to having a change-point. Therefore, the author derives a distribution for the threshold that is free of nuisance parameters supposing that when the sample increases the threshold effect goes to zero. In practice the procedure to obtain the confidence interval for the thresholds is based on the derived asymptotic distribution of a LR test for $r=r_{0}$. The idea is to use the sum of squared residuals calculated for all $\mathbf{r} \in[\underline{r}, \bar{r}], S_{n}(r)$ and to plot against $r$. Then, the limits of the confidence interval are defined by $S(\hat{r}) \pm \hat{\sigma}^{2} c$, where $\hat{\sigma}^{2}$ is the variance of the residuals of the threshold model and $c$ is an asymptotic critical value of the distribution of the LR statistic which depends on the coverage of the confidence interval ( $c=6.53$ for a $95 \%$ confidence interval). Even though this method has not been applied to multivariate models, one could use these results and the results of Tsay (1998) to employ $S(\hat{r})=\operatorname{tr}\left(\varepsilon(\hat{\mathbf{r}})^{\prime} \varepsilon(\hat{\mathbf{r}})\right)$ and $\hat{\sigma}^{2}=\operatorname{tr}\left(\varepsilon(\hat{\mathbf{r}})^{\prime} \varepsilon(\hat{\mathbf{r}})\right) /(\mathbf{k n})$.

Hansen (2000a) has also shown that when the sample is large, the distribution of the autoregressive coefficients is normal because the uncertainty arisen from the threshold estimation is small.

The confidence intervals proposed by Gonzalo and Wolf (2001) are calculated using procedures based on subsampling. The advantage is that it does not need the assumption that the threshold effect vanishes, but it can only be employed to calculate confidence intervals of threshold univariate models with two regimes. 


\subsection{Specification of number of regimes and of lags.}

The definition of the number of regimes can be done either by a supLR test or a sequential procedure with a penalty function. The first procedure was suggested by Hansen (2000b) and applied by Clements and Galvão (2003a) for TVARs assuming a two-regime TVAR under the null and a three-regime TVAR under the alternative. The empirical distribution of the test is calculated by bootstrap in the same way as it would be in testing linearity. The sequential procedure proposed by Gonzalo and Pitarakis (2002) requires that for each new threshold estimated using a sequential procedure a penalty function is evaluated. The penalty function depends on the number of estimated parameters evaluated comparatively with changes in the fit. The authors suggested penalty functions similar to those of the Schwarz criterion in order to choose accurately the number of regimes.

In his seminal paper, Tsay (1998) suggested the Akaike criterion to define the number of regimes, but the simulation results presented by Gonzalo and Pitarakis (2002) to univariate models suggest that the Schwarz criterion is more appropriate. The application of economic theory to identify the number of regimes is another technique employed in the literature. Anderson (1997) applies a model with three regimes supported by the theoretical effect of transaction costs.

Finally, likewise most of the VAR literature, the autoregressive order is chosen by an information criteria, as most convenient being in this case the Schwarz criterion.

\subsection{Impulse Response Functions.}

Generalized impulse response functions are an instrument used to evaluate the response to shocks in threshold VARs. The responses depend on the size and the sign of the shock, the history when the 
shock hits the system and the assumption about shocks hitting the economy in the future. The generalized responses proposed by Koop et al. (1996) suppose that shocks with mean 0 and variance $\hat{\Sigma}$ hit the system in the future. This is implemented bootstrapping the residuals of the estimated VAR. A natural way of determining a different set of histories (also employed by Altissimo and Violante (2001)) is to use the matrix of past data $X_{t-1}$ conditional on the regime, or to specific economic situations. Artis et al. (2003) show that this can be employed to characterize different transmission mechanisms given some economic conditions. Another important definition is the type of shock that hits the economy at $t$. Altissimo and Violante (2001) calibrated the shocks for a system with output and unemployment by identifying two typical shocks: an aggregative and a reallocative. Alternatively, Artis et al. (2003) employ a identification of shocks that resembles Cholesky decomposition. In addition, Van Dijk et al. (2000) assume that the shocks are drawn randomly from a normal distribution with variance that is a multiple of the residual variance matrix.

Formally, the generalized response of the $k$ series in $y_{t}$ to the shocks $v_{t}$ at horizon $n$ conditional on the history $\Omega_{t-1}$ is defined as:

$$
G I_{Y}\left(n, v_{t}, \Omega_{t-1}\right)=E\left[y_{t+n} \mid v_{t}, \Omega_{t-1}\right]-E\left[y_{t+n} \mid \Omega_{t-1}\right]
$$

Given the matrix of past data at $t \Omega_{t-1}=X$ (as defined in section 2.1), this matrix of histories is partitioned to obtain GIs conditional on the regime. For example, in the case of a two-regime TVAR the first partition $\Omega_{t-1}^{1}$ has the rows of $\Omega_{t-1}$ such that $I\left(w_{t-d} \leq r\right)$. GIs are computed for determined matrix of shocks $v$ that can have different combinations of $k \times 1$ set of shocks. Koop et al. (1996) describe different algorithms to compute generalized responses. 
An example of an algorithm to obtain $G I_{Y}\left(n, v_{i}, \Omega_{t-1}^{j}\right)$, which is the GI at horizon $n$ conditional on a type of shock in $v$ and one subset of histories of $\Omega_{t-1}$, is:

(1) Pick one row of shocks from the matrix $v_{l}$ and pick one of the subsets $\Omega_{t-1}^{i}$ of the matrix $\Omega_{t-1}$, where $l=1, \ldots, L$ and $i=1, \ldots, s$

(2) Pick one of the rows of $\Omega_{t-1}^{j}$.

(3) Use these vectors to compute $y_{t}^{s, m}=f\left(\Omega_{t-1}, \theta\right)+v_{l}$, where $\theta$ is a vector with all the estimated parameters of the model. This calculates the impact of the shock.

(4) Draw a sub-sample $\epsilon^{*}$ of size $N+1$ by bootstrapping from the residuals $\epsilon$.

(5) Use $\epsilon^{*}$ and the estimated TVAR to get $y_{t}^{n s, m}, \ldots, y_{t+N}^{n s, m}$. This calculates a sequence that describes the dynamic of the system when there is not a shock.

(6) Use $y_{t}^{s, m}$, the first $N$ observations of $\epsilon^{*}$ and the estimated TVAR to get $y_{t+1}^{s, m}, \ldots, y_{t+-N}^{s, m}$. This computes the dynamic effect of the shock. .

(7) Repeat steps 3 to $6 M$ times. Thus, obtain $E\left[y_{t+n} \mid \Omega_{i}^{j}, v_{i}\right]=$ $\frac{1}{M} \sum_{m=1}^{M} y_{t+n}^{s, m}$ and $E\left[y_{t+n} \mid \Omega_{i}^{j}\right]=\frac{1}{M} \sum_{m=1}^{M} y_{t+n}^{n s, m}$. In this way, steps 3 to 6 are aimed at calculating the conditional expectations.

(8) Pick another row of $\Omega_{t-1}^{j}$ and repeat the procedure from 3 to 7 until all rows are considered.

(9) Average the conditional means over stories to get $E\left[y_{t+n} \mid \Omega_{t-1}^{i}\right.$, $\left.v_{l}\right]$ and $E\left[y_{t+n} \mid \Omega_{t-1}^{i}\right]$, so $G I_{Y}\left(n, v_{l}, \Omega_{t-1}^{i}\right)=E\left[y_{t+n} \mid \Omega_{t-1}^{i}, v_{l}\right]-$ $E\left[y_{t+n} \mid \Omega_{t-1}^{i}\right]$.

(10) Select another combination of shock in $v_{l}$ and subset of histories $\Omega_{t-j}^{j}$ and repeat steps 2 to 9 until all possibilities are exhausted. This will generate a set of different GIs conditional on the shock and the set of histories. 
Note that it is recommended to generate data from a 2R-TVAR, for example, based on the following formulation: $y_{t}=\left[c_{1}+A_{1,1} y_{t-1}+\right.$ $\left.\ldots+A_{1, p} y_{t-p}+\varepsilon_{t}^{* 1}\right] I_{1}\left(w_{t-d} \leq r\right)+\left[c_{2}+A_{2,1} y_{t-1}+\ldots+A_{2, p} y_{t-p}+\right.$ $\left.\varepsilon_{t}^{* 2}\right]\left(1-I_{1}\left(w_{t-d} \leq r\right)\right)$, where $\varepsilon_{t}^{* 1}$ and $\varepsilon_{t}^{* 2}$ are bootstrapped from $\epsilon$, conditional on the regime. This means that information of the regime dependent covariance matrices are employed to the computation of the GIs.

Because of parameter uncertainty, inference on the GIs for each horizon is based on confidence intervals. Bootstrap can be employed to get the extreme values of an empirical $95 \%$ confidence interval. The distribution of the GI values for each horizon, conditional on the same set of histories and type of shock, is built by simulating $R$ samples of size $T$ using the estimated parameters and bootstraps from the residuals. Then these samples are employed to re-estimate the model and to re-calculate the GIs using the described algorithm. Note that the bootstrap procedure is heavily computational intensive: when the number of TVARs to have their generalized impulse responses computed is large, the computation time of personal computers may be measured in weeks.

\subsection{Forecasting.}

The computation of forecasts from TVARs is not equivalent to the VAR iterative procedure employing the matrix of coefficients: The expected value at $t+h$ conditional on the information until $t$ is

$$
E\left[y_{t+h} \mid \Omega_{t}\right]=\int_{-\infty}^{\infty} E\left[y_{t+h} \mid y_{t+h-1}\right] g\left(y_{t+h-1} \mid \Omega_{t}\right) d y_{t+h-1}
$$

where $g\left(y_{t+h-1} \mid \Omega_{t}\right)$ is conditional distribution. The problem is that there is no analytical solution for this integral because $y_{t+h-1} \mid \Omega_{t}$ depends non-linearly on $y_{t}$, so that the expected value at $t+h-1$ 
of the non-linear function that depends on $\theta$ and $y_{t}$ is not the same as the non-linear function applied to the expected value at $t+h-$ 1. Granger and Teräsvirta (1993) describe many solutions for this problem, but the most successful procedures employed in applied work consist of approximating the value of the integral by Monte Carlo simulation or by bootstrap. Clements and Smith (1997) and De Gooijer and Vidiella-I-Anguerra (2003) argue that there is not a significant difference between employing Monte Carlo simulation and bootstrap to compute forecasts.

Technically, a forecast algorithm for a TVAR using bootstrap is described as follows:

(1) Draw a sub-sample $\epsilon^{*}$ of size $h$ by bootstrapping from the residuals $\epsilon$.

(2) Use $\epsilon^{*}$, the coefficients of the TVAR and the information until $T$ to get a sequence of $h$ step-ahead forecasts $y_{T+1}^{n s}, \ldots, y_{T+h}^{n s}$.

(3) Repeat steps 1 and 2 rep times.

(4) Compute $\hat{y}_{T+h}$ for each step-ahead by averaging over replications, that is, $\hat{y}_{T+h}=\frac{1}{r e p} \sum_{n s=1}^{r e p} y_{T+h}^{n s}$.

\section{Threshold Vector Equilibrium Correction Models.}

The interest on threshold VECM in the literature arises from the ability of these models to characterize adjustment to the equilibrium depending on certain conditions. For example, Martens et al. (1998) argue that arbitrage between future and spot-index only occurs when the arbitrage relation is sufficiently large to compensate for transactional costs and other risks. Hansen and Seo (2002) define different adjustment of long and short-term interest rates from their long-run relationship depending on the deviations being either positive or negative. A TVECM for the first-difference of a $k$ vector of variables $x_{t}$ is: 
Multivariate Threshold Models: TVARs and TVECMs

$$
\Delta x_{t}=c_{i}+\sum_{j=1}^{p} A_{i, j} \Delta x_{t-j}+\alpha_{i} \beta^{\prime} x_{t-1}+\varepsilon_{t, i} \text { if } r_{i-1}<\beta^{\prime} x_{t-1} \leq r_{i}
$$

where $\beta^{\prime} x_{t-1}$ is the long-run equilibrium or the cointegration relationship. In the specific case that $k=2$ and there is only one vector of cointegration (popular case in the literature) $\beta^{\prime} x_{t-1}=$ $x_{1, t-1}-\beta x_{2, t-1}$. Thus, the long-run relationship between $x_{1}$ and $x_{2}$ is linear, but the adjustment to this equilibrium depends on the regime. Therefore, regimes with $\alpha$ near to zero represent no cointegration; and regimes with large $\alpha$ suggest that the short-run dynamics adjust to long-run disequilibria. In a three-regime case, the adjustment can occur differently if the deviations from the equilibrium are positive and large compared with negative ones (Clements and Galvão, 2003b).

Recently, De Gooijer and Vidiella-I-Anguerra (2003) proposed a level TVECM (LTVECM) that has $\beta$ changing conditional regime, that is:

$$
\begin{aligned}
\Delta x_{t}= & \left(c_{1}+\sum_{j=1}^{p} A_{1, j} \Delta x_{t-j}+\alpha_{1} \beta_{1}^{\prime} x_{t-1}+\varepsilon_{t, 1}\right) I\left(\beta^{\prime} x_{t-1} \leq r\right)+ \\
& \left(c_{2}+\sum_{j=1}^{p} A_{2, j} \Delta x_{t-j}+\alpha_{2} \beta_{2}^{\prime} x_{t-2}+\varepsilon_{t, 2}\right)\left(1-I\left(\beta^{\prime} x_{t-1} \leq r\right)\right) .
\end{aligned}
$$

In this case, depending whether the deviations from the equilibrium are larger or smaller than the threshold, the adjustment will occur to a different long-run equilibrium. These dynamics is shown by the authors to improve long-horizon forecasts. 


\subsection{Testing Threshold Cointegration and the estimation of TVECM.}

Balke and Fomby (1997) proposed a two step procedure to test non-linearity in cointegrated systems. The first step is to test for cointegration using a standard method, such as OLS and an ADF test or the Johansen ML procedure. The second step tests for nonlinearity in the cointegrating combination, using a test of linearity against SETAR structure, such as Hansen (1996). The testing method leads to the estimation of a TVECM in three steps. In the first one, the cointegration relation is estimated by OLS. In the second one, a TAR is estimated for the residuals of the normalized cointegration vector. Finally, thresholds computed in the second step are employed to estimate a TVECM, without need for new threshold estimation.

Testing for cointegration (as in Step 1 of Balke and Fomby (1997)) may have low power when the process is $I(0)$ but exhibits non-linear mean reversion: see, for example, the Monte Carlo evidence in Balke and Fomby (1997). Enders and Granger (1998) proposed a test for a unit root against asymmetric adjustment under the alternative hypothesis, whereby the process is either a two-regime TAR or an M-TAR (Momentum-TAR). For the former, the rate of autoregressive decay depends on whether the variable is above or below some threshold, and for the latter, on whether the variable is increasing or decreasing. Enders and Siklos (2001) generalize this test for cointegration, i.e., when the variable is an estimated residual from an Engle-Granger static regression of one integrated variable on another (or several), which implies to test the residual $w_{t}=x_{1, t}-\hat{\beta} x_{2, t}-\hat{\mu}$, where $(\hat{\beta}, \hat{\mu})$ are OLS estimates. The null hypothesis is now interpreted as a test that $x_{1}$ and $x_{2}$ are not cointegrated, and the alternative is of 'asymmetric cointegration', whereby 
the series can be shown to be related by a non-linear equilibriumcorrection model. For example, when the threshold is zero, the following regression is run:

$$
\Delta w_{t}=I_{t} \rho_{1} w_{t-1}+\left(1-I_{t}\right) \rho_{2} w_{t-1}+\varepsilon_{t}
$$

where, for the TAR alternative, $I_{t}=1$ if $w_{t-1} \geq 0$, and is zero otherwise, and for testing against the M-TAR alternative, $I_{t}=1$ if $\Delta w_{t-1} \geq 0$, and is zero otherwise. They obtain by simulation critical values of two test statistics of the null that $\rho_{1}=\rho_{2}=0$ (against both TAR and M-TAR alternatives). These are an $F$-test of $\rho_{1}=\rho_{2}=0$ and a ' $t$-max' statistic, which is the larger of the two individual $t$-tests of $\rho_{1}=0$ and $\rho_{2}=0$. A Monte Carlo evaluation of these tests suggests that the $F$-test is to be preferred, and has reasonable power when the process is an M-TAR, but otherwise it is dominated by the ADF test. Further complications arise when the threshold is not known (the authors assume that it is zero for $w_{t}$ ). The results of cointegration tests are employed to decide between a M-TVECM and a TVECM. The authors suggest to estimate the threshold as in the second step suggested by Balke and Fomby and use different dynamics only in the adjustment to the long-run equilibrium.

Instead of testing $w_{t}$ for non-linearity as outlined above, threshold effects can be tested for by comparing the VECM against TVECM. This requires a multivariate extension of Hansen (2000b) employed by Clements and Galvão (2003a) and Lo and Zivot (2001). We denote the estimated covariance matrices of TVECM with two regimes as $\hat{\Sigma}_{2}$, and let $\hat{\Sigma}_{1}$ be the covariance matrix of the VECM. An LR test for linearity against the two-regime specification is:

$$
L R_{12}=T\left[\ln \left(\operatorname{det}\left(\hat{\Sigma}_{1}\right)\right)-\ln \left(\operatorname{det}\left(\hat{\Sigma}_{2}\right)\right)\right],
$$

where $T$ is the number of observations. Similar test can be employed 
to test linearity against a three-regime TVECM.

The asymptotic distribution is an extension of Hansen (1996), as argued by Hansen and Seo (2002). Bootstrap can be used to obtain a finite sample approximation. The bootstrap distribution is calculated from the data generated by the linear model by re-sampling its residuals. The residuals are corrected for heteroscedasticity before re-sampling, using a regression of the squared residuals on the squared regressors, as described in Hansen (2000b). This approach suggests a two step procedure for the estimation: (1) estimate the cointegration relation by OLS; (2) estimate a TVECM using grid search to minimize $\operatorname{det}(\hat{\Sigma}(\theta))$ or $\operatorname{tr}[\hat{\Sigma}(\theta)]$.

Instead of firstly estimating the cointegrating relationship, Hansen and Seo (2002) suggest a single step approach that jointly estimates the cointegrating vector and the defining characteristics of the regimes. Their method involves estimating a two-regime TVECM at each point in a suitable grid of values defined over both $\beta$ and $r$, and choosing the pair $(\hat{\beta}, \hat{r})$ that minimizes $\log |\hat{\Sigma}(\hat{\beta}, \hat{r})|$ (where $\hat{\Sigma}$ is the estimated residual covariance matrix). In practice, because of the limitations in the estimation by grid search, the delay is given, and the TVECM is restricted to having two regimes. The authors also proposed an 'LM-like' non-linearity test. LM tests are calculated with $\beta=\hat{\beta}$, the MLE in the linear VECM, and where $r$ takes on each of a pre-assigned set of values in the interval $\left(r_{L}, r_{U}\right)$ (such that a minimum number of observations occur in each regime, say $10 \%)$. The test statistic is the supremum:

$$
S u p L M=\sup _{r_{L} \leq r \leq r U} L M(\hat{\beta}, r)
$$

Hansen and Seo (2002) derive the asymptotic distribution of this statistic, which is similar to the Hansen (1996) distribution for the 
univariate case, and propose a fixed bootstrap procedure to obtain a finite sample approximation.

The estimation of the LTVECM as suggested by De Gooijer and Vidiella-I-Anguerra (2003) can be done by two-stage least squares and maximum likelihood. In both cases, the confidence interval estimated of $\beta$ in the linear case is employed to define the size of the grid for $\beta_{i}$ and also the grid for $r$. This is a generalization of the procedure suggested by Hansen and Seo (2002).

\section{Applications ${ }^{1}$.}

In this section I apply some of the techniques discussed in the previous section in two examples. Both examples analyze US data. The first example applies a TVAR to model the spread as a leading indicator in order to predict the probability of recessions. The second example tests threshold cointegration and estimates a TVECM for the dynamic behavior between long- and short-term interest rates.

\subsection{TVAR: Spread as Leading Indicator.}

The literature documents that the spread between a 10-year and a 3-month interest rate is a good predictor for a US recession (Stock and Watson, 2001), however the spread is not able to predict the strength of the expansion (Galbraith and Tkacz, 2000). This suggests a 2R-TVAR for $\left[\Delta y_{t}, S_{t}\right]^{\prime}$. The data employed in this application is obtained from the FRED database from the Fed of Saint Louis. The series are quarterly and span from 1953:2 to 2002:3, with the 10-year and the 3-month interest rates converted from monthly to quarterly employing averaging.

In the first part of this application I test linearity against the 2R-TVAR and also a 3R-TVAR. We also test whether the 2R-TVAR

\footnotetext{
${ }^{1}$ Codes written in Gauss are available on request to replicate the results of this section.
} 
can be rejected in favor of the 3R-TVAR. These tests are done for the full sample. I employ a supLR test with bootstrapped empirical distribution as employed by Clements and Galvão (2003a) and Lo and Zivot (2001).

The code written in Gauss (Aptech Systems) has the following structure:

(1) Definition of global parameters: $l$ is the number of endogenous variables (or $k$ ); $p$ is the autoregressive order; $d \max$ is the maximum delay considered in the grid search; $l c$ is the location of the transition variables, $p r$ is the minimum proportion of observations in each regime and boot is the number of bootstrap replication.

(2) Loading and organization of data.

(3) Estimation of thresholds and delay for a 2R-TVAR and a 3RTVAR using a grid search to minimize $\operatorname{det}\left(\hat{\Sigma}\left(\theta_{\mathbf{L}} \mid \theta_{\mathbf{N L}}\right)\right)$. For the estimated values $\theta_{N L}, \hat{\Sigma}_{2}$ and $\hat{\Sigma}_{3}$ are saved, which is employed to compute the supLR statistic.

(4) Given $\theta_{N L}, \theta_{L}$ is computed by OLS.

(5) For each replication, data is simulated from the VAR using bootstrap correcting for possible general heteroscedasticity of the residuals.

(6) Repeat of step 3 with the simulated data, having the supLR statistic saved.

(7) Steps 5 and 6 are repeated until all replications (boot) are computed.

(8) Calculation of the p-value of the tests counting the proportion of the replication in which the $\sup L R_{i}$ is larger than the statistic computed in step 3 . 
Table 1 Estimates and Tests for Example 1.

\begin{tabular}{ll}
\hline 2R-TVAR: $p=2 ; d=1 ; r=1.79 ; S I C=-1.303$ \\
3R-TVAR: $p=2 ; d=1 ; r_{1}=0.25 ; r_{2}=1.79 ; S I C=-1.120$ \\
\hline $\mathrm{LR}_{12}:$ & $51.096[0.062]$ \\
$\mathrm{LR}_{13}:$ & $69.60[0.078]$ \\
$\mathrm{LR}_{23}:$ & $18.50[0.752]$ \\
\hline
\end{tabular}

To test the TVAR with two regimes against the one with three regimes, one can employ similar procedure, simulating data from the 2R-TVAR in step 5 and estimating the 2R-TVAR and the 3R-TVAR to get the $\operatorname{supLR}_{i}$ statistics in step 5 .

The results of these tests are presented in Table 1 . The null hypothesis of linearity is rejected against the 2R-TVAR and the 3RTVAR alternatives at $10 \%$ significance with heteroscedasticity consistent statistics, but the specification test favors the 2R-TVAR. I decide to employ both models to compute the probability forecasting.

The probability of recession is defined in two ways by Fair (1993): (A) probability of two consecutive periods of negative growth in the next five quarters and (B) probability of two periods of negative growth in the next five quarters. The definitions are based on the rule of thumb that a recession is defined after two quarters of negative growth but this is evaluated in a five-quarter window to mimic conditions when dating turning points. This event can be dated using real quarterly GDP growth and the information is presented as a binary variable that is equal to 1 when the event occurs. The predicted probabilities from the 2R-TVAR and the 3R-TVAR are obtained by applying a small modification in the algorithm described in section 2.6:

(1) Draw a sub-sample $\epsilon^{*}$ of size $h$ by bootstrapping from the residuals $\epsilon$. The bootstraps are built in such a way that the residuals are assumed to have different variance conditional on the regime. 
(2) Use $\epsilon^{*}$, the coefficients of the TVAR and the information up to $T$ to get a sequence of 5 step-ahead forecasts $y_{T+1}^{n s}, \ldots, y_{T+5}^{n s}$.

(3) Repeat steps 1 and 2 rep times.

(4) Apply the rule to identify event A or B in each one of the rep sequences of forecasts computed till step 3 . The predicted probability is the proportion of times over all the replications that the event was identified.

The algorithm to estimate and to forecast with TVARs is incorporated in a larger procedure to generate recursive out-of-sample forecasts for the inclusion of a new information that goes from $t_{0}$ until $T-t_{0}-5$. For each new forecast origin, the TVARs are reestimated including the autoregressive order, computed to minimize SIC. As a product of the procedure, I obtain the observed events and the probability of the events forecasted with information until $t-1$.

The probabilities for event A predicted from the 2R-TVAR and the 3R-TVAR are presented in Figure 1 together with the actual values for $t_{0}=130$. Two recessions occur in the out-of-sample period: one in the 1990-91 period and another 10 years later in 2001. The information in the spread did not characterize probabilities of recessions higher than $50 \%$ in 1990/91, but this happened in the last/actual recession. Another important point is that there is no false alarms in the period. Figure 2 presents the estimated $r, p$ and $\mathrm{d}$ for each forecast origin. This figure can tell us about the stability of the model to the inclusion of new information. There are only two main changes in the estimated parameters: one after the 1991 recession and another after 1998. The interesting point is that the parameters change in such a way that they are the same before 1991 and after 1998. Therefore, the estimation of the parameters of the model are relatively robust, supporting the evidence that TVAR models are able to capture interesting behavior of the data. 
Multivariate Threshold Models: TVARs and TVECMs

Predicting Probability of Recession using the Spread from TVARs

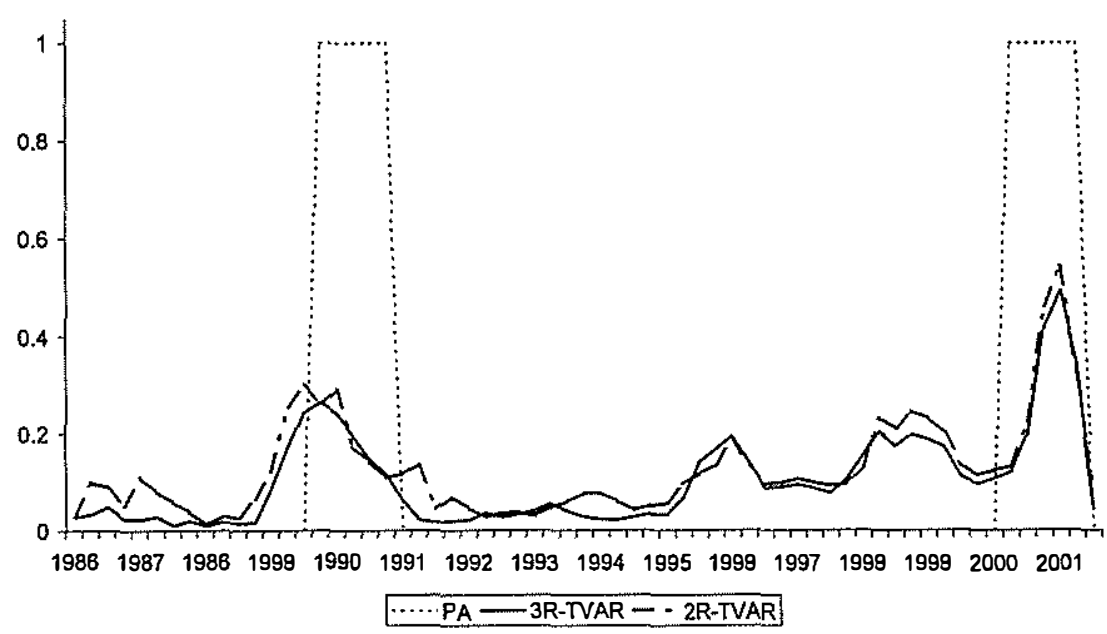

Figure 1 Probability of Event A (out-of-sample) computed for 2R-TVAR and 3R-TVAR.

4.2 TVECM: Expectations theory and term structure of interest rate.

In this example I aim at reproducing the threshold cointegration test and the procedure to estimate a TVECM suggested by Hansen and Seo (2002). The application of the TVECM is motivated by the expectations theory of the term structure of interest rates that the spread between the long-term and the short-term interest rates is the long-run equilibrium of a VECM system for the first-difference of the interest rates (Hall et al., 1992). This implies that the spread must be $I(0)$, but this is not the case when employing ADF tests. Instead of rejecting the expectations theory based on the results of the ADF test, one could argue that the spread behaves as a random walk in a regime and it is mean-reverting in another regime, such that 
the spread only predicts changes in the short-rates in one regime. The presence of transaction costs supports the specification of a 3RTVECM: the rates will converge to the equilibrium only when the deviations from the equilibrium are large enough. In this example, I consider only 2R-TVECMs to be able to estimate the cointegration vector together with the threshold (for example of a 3R-TVECM with similar dataset, see Clements and Galvão (2003b)).

Estimates of $r, d$ and $p$ for each forecast origin

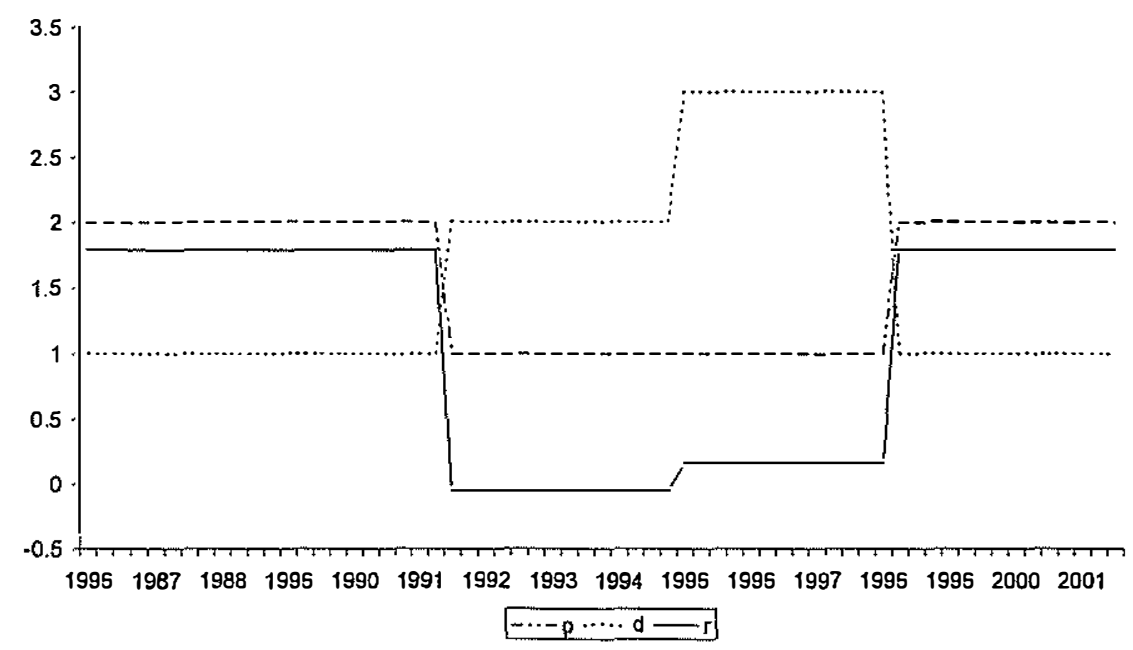

Figure 2 Estimates of threshold, delay and autoregressive order from the 2R-TVAR for each forecast origin.

The data employed in this application was obtained in the Fred (Federal Reserve of St. Louis) database for the 3-month T-bill and the 10-year T-bond from 1953:3 to 2002:11, Hansen and Seo (2002) employ the McCulloch-Kwon database instead.

The algorithm developed by Hansen and Seo (2002) has the following global parameters: $k$ is the number of lags in the VAR; $g n$ is the size of the grid for $r$ and $b n$ is the size of the grid for $\beta$; trim is 
the minimum proportion of observations in each regime; boot is the number of bootstrap replications; _cvalue is an indicator whether $\beta$ is estimated by ML in a first step and _coint is an indicator whether $\beta$ is jointly estimated with $r$ to obtain the TVECM. Generally speaking, the algorithm has three main steps:

(1) $\beta$ is estimated by ML and a confidence interval is built using the changes in the maximum of the likelihood function when small deviations from the estimated value are imposed.

(2) The confidence intervals are employed to define the limits of a grid of $b n$ points. Based on these limits, grid for $r$ is calculated given that the values of the transition variable are such that $w_{t-1}=r(l)-\beta r(s)$.

(3) Using the defined grids, a search is done to minimize $\log |\hat{\Sigma}(\hat{\beta}, \hat{r})|$. Then, following the $\theta_{N L}$ estimates, $\theta_{L}$ is calculated.

The test of linearity is actually applied using the $\hat{\beta}$ obtained in step 1 and doing search only to obtain $\hat{r}$. The statistic is a supLM. The empirical distribution of this statistic is computed using fixed regressor bootstrap and parametric bootstrap. In the first case, the regressors $(X)$ are supposed to be fixed and only $y$ is randomized. In the second case, the bootstrap procedure re-estimates all the models for each step using simulated data as the supLR test discussed in the previous example.

Assuming $p=2$, the sup $L M$ statistic is 26.40 with p-value equal to 0.03 using fixed bootstrap and equal to 0.058 using parametric bootstrap (based on 1000 replications). This suggests evidence of threshold cointegration in the data. The other estimates are $\hat{\beta}=$ 0.932 and $\hat{r}=0.472$ defining $10 \%$ of the observations in the lower regime. The short-run adjustment to the cointegration vector is only strong in the equation of the short-term rate in the lower regime. 


\section{Evaluation.}

Most of the evaluation of TVARs and TVECMs have been done by their forecast performance (see forthcoming issue (2003) of International Journal of Forecasting). They improve forecasts for some regimes (such as recessions), are good to predict the probability of some rare events, and TVECMs only improve point forecasts at short-horizons (compared with VECMs) when the cointegration vector does not change over regimes. Diagnostic tests are rarely applied to these models and the development of appropriate diagnosis tests is needed.

Comparing with another non-linear specifications, such as smooth transition VARs, TVARs have the disadvantage of having a difficult asymptotic theory. However, TVARs are relatively easy to estimate and allow to generate forecasts and impulse response functions with regime-dependent variances. Markov-Switching VARs are easily employed to obtain forecasts, given that simulation methods are not needed, but they have the disadvantage of having regimes determined by an unobserved variable that complicates the interpretation of the results. There are not many comparisons between threshold and other classes of non-linear models. The results for univariate models show that is hard to discriminate classes of non-linear models using forecasting (Clements and Krolzig, 1998; Clements et al., 2000.

Submitted in January 2003. Revised in February 2003. 


\section{References}

Altissimo, F. and Violante G. L. 2001. "The non-linear dynamics of output and unemployment in the US", Journal of Applied Econometrics 16: 461-86.

Anderson, H. M. 1997. "Transaction costs and non-linear adjustment towards equilibrium in the US Treasury bill market", $O x-$ ford Bulletin of Economics and Statistics 59: 465-84.

Artis, M., Galvão, A. B. C. and Marcellino, M. 2003. "The transmission mechanism in a changing world", European University Institute (mimeo) .

Balke, N. S. and Fomby, T. B. 1997. "Threshold cointegration", International Economic Review 38: 627-45.

Clements, M. P., Franses, P. H., Smith, J. and Van Dijk, D. 2000. "On SETAR non-linearity and forecasting", Econometric Institute, Erasmus Rotterdam, Research Report 1999-14/A.

Clements, M. P. and Galvão, A. B. C. 2003a. "A comparison of tests of non-linear cointegration with an application to the predictability of the US term structure of interest rates", International Journal of Forecasting forthcoming.

Clements, M. P. and Galvão, A. B. C. 2003b. "Testing the expectations theory of the term structure of interest rates in threshold models", Macroeconomic Dynamics forthcoming.

Clements, M. P. and Krolzig, H.-M. 1998. "A comparison of the forecast performance of Markov-switching and threshold autoregressive models of US GNP", Econometrics Journal 1: C47-C75.

Clements, M. P. and Smith, J. 1997. "The performance of alter- 
native forecasting methods for SETAR models", International Journal of Forecasting 13: 463-75.

De Gooijer, J. G. and Vidiella-I-Anguerra, A. 2003. "Forecasting threshold cointegrated systems", International Journal of Forecasting (forthcoming).

Enders, W. and Granger, C. W. J. 1998. "Unit-root tests and asymmetric adjustment with an example using the term structure of interest rates", Journal of Business and Economics Statistics 16: 304-11.

Enders, W. and Siklos, P. L. 2001. "Cointegration and threshold adjustment", Journal of Business and Economic Statistics 19: $166-176$.

Fair, R. C. 1993. "Estimating event probabilities from macroeconometric models using stochastic simulation", in J. H. Stock and M. W. Watson (eds), Business Cycles, Indicators, and Forecasting, NBER, University of Chicago Press, Chicago, pp. 157-78.

Galbraith, J. W. and Tkacz, G. 2000. "Testing for asymmetry in the link between the yield spread and output in the G-7 countries", Journal of International Money and Finance 19: 657-672.

Gallant, A. R. 1987. Nonlinear Statistical Models, John Wiley, New York.

Galvão, A. B. C. 2002. "Structural breaks and non-linearities for predicting the probability of US recessions using the spread", European University Institute, mimeo. Preliminary version at XXIII Encontro Brasileiro de Econometria, Anais, 2001, p. 62342.

Gonzalo, J. Pitarakis, J.-I. 2002. "Estimation and model selection 
based inference in single and multiple threshold models", Journal of Econometrics 110: 319-52.

Gonzalo, J. and Wolf, M. 2001. "Subsampling inference in threshold autoregressive models", Universitat Pompeu Fabra, Economics Working Paper 573.

Granger, C. W. J. and Teräsvirta, T. 1993. Modelling Nonlinear Economic Relationships, Oxford University Press, Oxford.

Hall, A. D., Anderson, H. M. and Granger, C. W. J. 1992. "A cointegration analysis of Treasury bill yields", Review of Economics and Statistics 74: 116-26.

Hansen, B. E. 1996. "Inference when a nuisance parameter is not identified under the null hypothesis", Econometrica 64: 413-30.

Hansen, B. E. 2000a. "Sample splitting and threshold estimation", Econometrica 68: 575-603.

Hansen, B. E. 2000b. "Testing for linearity", in D. A. R. George, L. Oxley and S. Potter (eds), Surveys in Economic Dynamics, Blackwell, Oxford, pp. 47-72.

Hansen, B. E. and Seo, B. 2002. "Testing for two-regime threshold cointegration in vector error correction models", Journal of Econometrics 110: 293-318.

Koop, G., Pesaran, M. H. and Potter, S. M. 1996. "Impulse reponse analysis in nonlinear multivariate models", Journal of Econometrics 74: $119-47$.

Lo, M. C. and Zivot, E. 2001. "Threshold cointegration and nonlinear adjustment to the law of one price", Macroeconomic Dynamics 5: 533-76. 
Martens, M., Kofman, P. and Vorst, T. C. F. 1998. "A threshold error-correction model for intraday futures and index returns", Journal of Applied Econometrics 13: 245-63.

Stock, J. H. and Watson, M. W. 2001. "Forecasting output and inflation: The role of asset prices", NBER Working Paper $\mathbf{8 1 8 0 .}$

Tsay, R. S. 1989. "Testing and modeling threshold autoregressive processes", Journal of the American Statistical Association 84: 231-40.

Tsay, R. S. 1998. "Testing and modeling multivariate threshold models", Journal of American Statistical Association 93: 11881202.

Van Dijk, D., Franses, P. and Boswijk, P. 2000. "Asymmetric and common absorption of shocks in nonlinear autoregressive models", Econometric Institute, Erasmus Rotterdam, Research Report 2000-01/A. 



\section{NOTE}

\section{ADRIANO ROMARIZ DUARTE AWARD}

In 1994 the Brazilian Econometric Society instituted the Adriano Romariz Duarte Award. Since then, the award has been given every even year to the best article published in the Brazilian Review of Econometrics. The next award will be given to the articles published in volumes 21 and 22 .

According to the to the rules governing the Award, the Editor will appoint an award commission which will select the winnning article.

A list of previous award winners is:

\section{4}

"Strategic Behavior in Ascending-Price Multiple-Object Auctions", by Flávio Marques Menezes.

\section{6}

"Déficit Público, A Sustentabilidade do Crescimento das Dívidas Interna e Externa, Senhoriagem e Inflação: Uma Análise do Regime Monetário Brasileiro", by Affonso Celso Pastore.

"Mecanismos de Admissão de Candidatos à Instituiçōes. Modelagem e Análise à Luz da Teoria dos Jogos", by Marilda Sotomayor.

\section{8}

"Estimadores Corrigidos para Modelos SUR Não-Lineares", by Gauss M. Cordeiro and Klaus L.P. de Vasconcellos.

"Cournotian Competition under Knigthian Uncertainty", by Sérgio Ribeiro da Costa Werlang and Hugo Pedro Boff.

\section{0}

"The Slippery Slope: Explaining the Increase in Extreme Poverty in Urban Brazil, 1976 - 1996", by Francisco H. G. Ferreira and Ricardo Paes de Barros. 



\section{Subscription Form}

To become a subscriber to The Brazilian Name

Review of Econometrics you should fill out this form and send it to:

Institution

The Brazilian Review of Econometrics - $\quad$ Address

AVC: Angela Maria Bevilacqua

Praia de Botafogo, $190-10^{\circ}$ andar -

City

sala 1032

22253-900 Botafogo, Rio de Janeiro, RJ., Brasil

Tel. (5521) 2551-4658

Postal Code

Fax (5521) 2552-4898

sbe@fgv.br - http: //www.sbe.org.br

Subscriptions

Country

Telephone

US\$100/R $\$ 150,00$

Institutions and new subscribers

Fax

E-Mail

US\$ 50 / R $\$ 75,00$

Renewals for individual subscribers

Year of Subscription

US\$25/R \$ 37,50 Students

Amount in US\$ ou R\$ 


\section{Methods of Payment}

\section{Checks}

Please send a check with the value of your subscription payable to Sociedade Brasileira de Econometria which can be drawn in a Brazilian bank to the SBE office..

After we receive your check we will send you a receipt, as well as the issues of the Review that correspond to your subscription.

Checks and subscription form should be sent to:

SBE The Brazilian Review of Econometrics

A/C Angela Maria Bevilacqua

Praia de Botafogo, 190 - $10^{\circ}$ Andar - Sala 1032

22253-900 - Botafogo - Rio de Janeiro, RJ., Brasil

Tel. (5521) 2551-4658 - Fax (5521) 2552-4898

sbe@fgv.br - http: //www.sbe.org.br

\section{Bank Deposit}

A bank deposit must be made in the society's account at Banco do Brasil.

Please send us a fax (5521) 25524898 with a copy of your deposit slip attached to your subscription form. The fax is your proof of subscription.

Account Information

Banco do Brasil - Rio de Janeiro - RJ Brasil

Agência Botafogo

Número 0287-9

Account 112.842-6 
Payment with a Credit Card

Credit card Number

Expiration Date

Amount

Name of the Card

Signature

Date

We accept Diners, Master Card e Credicard

Send subscription form to

SBE The Brazilian Review of Econometrics - Revista de Econometria A/C: Angela Maria Bevilacqua

Praia de Botafogo, $190-10^{\circ}$ andar - sala 1032

22253-900 Botafogo, Rio de Janeiro, RJ., Brasil

Tel. (5521) 2551-4658

Fax (5521) 2552-4898

sbe@fgv.br - http: //www.sbe.org.br 



\title{
Sub binission of Manuscripts to the Brazilian Review of Econometrics
}

1. Four copies of the original manuscript should be sent to:

\author{
Angela Maria Bevilacqua \\ Editorial Assistant, Brazilian Review of Econometrics \\ EPGE - Fundação Getulio Vargas \\ Praia de Botafogo, 190 - 10o. Andar \\ Rio de Janeiro, RJ 22253-900 Brazil.
}

'Two copies of the manuscript should not have the author's name indicated or revealed in any manner. The manuscripts must be accompanied by a submission Letter and be written in English or Portuguese. Submission of a paper is held to imply its contents represent original and unpublished work, and that it has not been submitted elsewhere. Manuscripts are always refereed and may be rejected, returned for specified revisions or accepted.

2. Manuscripts should have an opening page containing the title, the author's name(s), address(es), e-mail and affiliation. It should also contain a set of $\mathrm{Key}$ Words and Phrases, a primary and secondary Journal of Economic Literature classification for the manuscript and an Abstract in English of at most 150 words.

3. Manuscripts should be typed with double line spacing on standard size paper, preferably $8.5 \times 11$ inches, in a font size of 10 or $12 \mathrm{cpi}$. The typing area of all pages should be no more than $5.5 \times 8.5$ inches $(14 \times 21.6 \mathrm{~cm})$.

4. Tables should be typed as part of the text, but in such a way as to avoid confusion with text, extra space should be left above and below the table. Tables, including title, legend, label or number, should fit within the standard typing area and should not run over to the next page.

5. Graphs and other numbered figures should be separate from the text, sized to fit within the width and height of the typed pages and be ready for printing.

6. References should be indicated in the text by the author's name and the year of publication in parentheses. All references should then be collected in alphabetical order at the end of the manuscript.

7. Any acknowledgements, including citations to supporting grants and contracts, should be typed as text and placed before the references at the end of the manuscript. 


\title{
Submissāo de Manuscritos para a Brazilian Review of Econometrics
}

1. Quatro cópias do manuscrito original devem ser enviadas para:

\author{
Angela Maria Bevilacqua \\ Editorial Assistant, Brazilian Review of Econometrics \\ EPGE - Fundação Getulio Vargas \\ Praia de Botafogo, 190 - 10o. Andar \\ Rio de Janeiro, RJ 22253-900 Brazil.
}

Em duas cópias do manuscrito não deverá constar o nome do autor indicado ou revelado de nenhuma maneira. Os manuscritos deverão ser escritos em inglês ou português e acompanhados por uma carta de submissão. A submissão de um manuscrito implica que seu conteúdo é original, não publicado e que não está submetido para publicação a nenhum outro periódico. Os manuscritos são sempre julgados por pareceristas e podem ser rejeitados, devolvidos para revisōes específicas ou aceitos.

2. Os manuscritos devem ter uma página de abertura contendo o título, o(s) nome(s) do(s) autor(es), endereço(s), e-mail e afiliação. Também deverá conter uma série de Palavras-Chave e Frases , uma classificacão primária e secundária para o manuscrito de acordo com o sistema do Journal of Economic Literature e um Abstract em inglês de no máximo 150 palavras.

3. Os manuscritos devem ser digitados com espaço duplo, em papel tamanho padrão, preferencialmente $8.5 \times 11$ polegadas, com um tamanho de fonte 10 ou $12 \mathrm{cpi}$. A área total da página a ser digitada não deverá ser maior do que $5.5 \times 8.5$ polegadas $(14 \times 21.6 \mathrm{~cm})$.

4. As Tabelas devem ser digitadas como parte do texto, mas de maneira a evitar confusão com o mesmo, espaço extra deve ser deixado acima e abaixo da tabela. Tabelas, incluindo título, legenda, selo ou número, deverão ajustar-se à área de digitação e não deverão passar para a próxima página.

5. Gráficos e outras figuras numeradas devem ser separados do texto, com um tamanho que se ajusta à largura e altura das páginas digitadas para impressão.

6. As referências devem ser indicadas no texto pelo nome do autor e o ano da publicacão entre parênteses. Todas as referências deverão ser grupadas em ordem alfabética no final do manuscrito.

7. Quaisquer agradecimentos, incluindo citaçōes, permissōes de apoio e contratos, devem ser digitados no texto e colocados antes das referências no final do manuscrito. 